\title{
Vibration and Impact Analysis of Optimized Automotive Front Bumper
}

\author{
Mangesh P. Wagh \\ Post Graduate Student \\ Mechanical Engineering Dept. \\ AISSMS, COE, Pune, India
}

\author{
O. A. More \\ Associate Professor \\ Mechanical Engineering Dept. \\ AISSMS, COE, Pune, India
}

\begin{abstract}
This Safety is the major concern in automotive engineering because of rate of accident increasing worldwide. Generally, in most of the accident during front collision bumper hits the other vehicle. The main function of front bumper is to absorb the possible crash energy during collision and should have low weight apart from the safety. In automobile industries importance also given to fuel efficiency and emission gas regulation, that gives advantage to manufacturer in weight reduction of automotive. The main factor affecting bumper like shape optimization, impact condition $\&$ vibration are studied for design and analysis of front bumper to improve cross worthiness. Here shape geometry is studied to design the optimized structure of bumper and impact behaviour analysis is carried on it to find out energy absorption capacity also easiness of manufacturing studied parallelly. In this research, impact dynamic behaviour analysis of optimized front bumper without stiffener and with stiffener are carried out and compare their result against stress distribution, energy absorption, deformation and found that bumper with stiffener have more energy absorption capacity. Experimentally validate the natural frequencies obtained from FFT analyzer with Modal analysis using FEA software and those are closely matched. While building the prototype, found that designed bumper structure is easy to manufacture too.
\end{abstract}

Keywords-Bumper; Vibration; Stiffeners; FEA .

\section{INTRODUCTION}

World is now focused on the rapid developments in the various fields such as aerospace, space, automotive, electronics, and defense, infrastructure developments \& power generation. Automotive sector has emerged as booster to the economy of nations over worldwide. Nowadays rate of road accident is increasing worldwide so safety is prime important in automotive engineering and automotive manufactures are also looking to bring light weight and fuel-efficient vehicles in market. So, there is continual research on reducing the cost of vehicle as well as on improving passenger safety concerns. In automotive industries, factors, such as vehicle weight reduction and energy absorption through deformation but in a controlled manner of the frontal vehicle structure, is getting researcher major focus over the last few years. A bumper is front-most or Rear most part of automobile, ostensibly designed to allow the car to withstand in an impact without causing damage to the vehicle's safety and other systems. During high speed impact, they are not capable of reducing injury to vehicle occupants but being increasingly designed to mitigate the injury to pedestrians struck by cars. The ideal design of the bumper should take full advantage of the bumper plastic deformation to absorb most crash energy in automobile collisions [1]. The bumper structure designed to prevent or reduce physical damage to the front or rear ends of passenger motor vehicles in collision condition. They also protect other system of automobile. A good design of car bumper must provide safety for passengers and should have low weight [2]. During literature study found that automobile bumpers are designed to absorb the energy during front and rear impact of car such way that we can select best materials and geometry it should possess the above two requirements with minimum price [3]. Although the use of light weight parts helps in reducing fuel consumption and consequently lower carbon dioxide emissions, another stringent demand from the society is the passive safety obtained through energy absorbing bumper [4]. Automotive design with economy, safety, high fuel efficiency and aesthetics have been a great challenge to design engineers.

In the actual product design, finite element analysis methods have been extensive use to replace the crash tests and research results indicating the use of FEA software to simulate the real vehicle collision test has good agreement results with the real test, which can effectively substitute vehicle crash tests to conduct collision analysis. Computational tools of FEA helps in saving cost and time in studying economic design and enable alternative study on various materials and its properties under varying loads. So Finite Element Analysis is considered for analysis in this work.

In main objective of this work is to design an optimized and impact dynamic behavior bumper structure like crashworthiness by studying and analyzing different feasible shapes of front bumper along with other affecting parameters by using $3 \mathrm{D}$ modeling software and FEA software. In this work mild steel of $2.5 \mathrm{~mm}$ thickness is used to manufactured prototype of optimized bumper in order to find out its ease of manufacturability and to perform FFT analysis in order to find out natural frequency and will try to validate FEA results with experimental results.

\section{RESEARCH METHODOLOGY}

Based on Comprehensive study and analysis of key parameters of bumper through various research literature, bumper standards, crash analysis, actual working conditions, the bumper structural model is established. The bumper structure is optimized and enhanced the crashworthiness by iterating the bumper structure by considering the different feasible shape geometry, thickness, manufacturability and performing dynamic behaviour analysis by using FEA software for every iterated modelled bumper structure till to get optimized bumper with better result also Validated the improved natural frequencies obtained from manufactured bumper by experimentally with FEA software. 


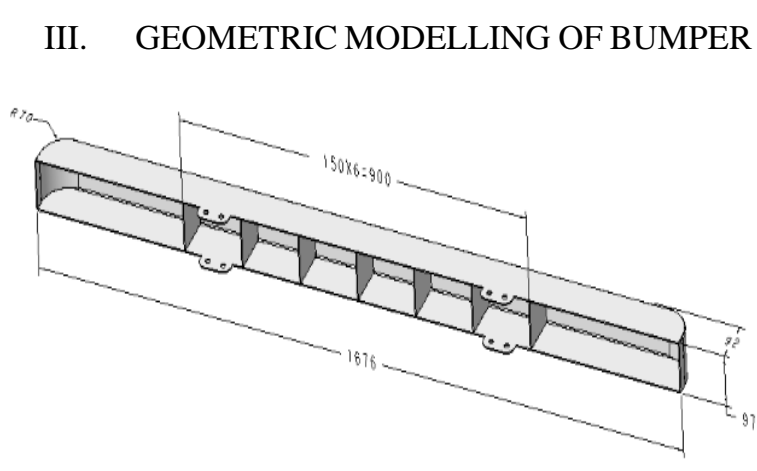

IV. FEA-MOdAL ANALYSIS OF BUMPER

\section{A. Optimized Bumper}

1) Bumper Geometry

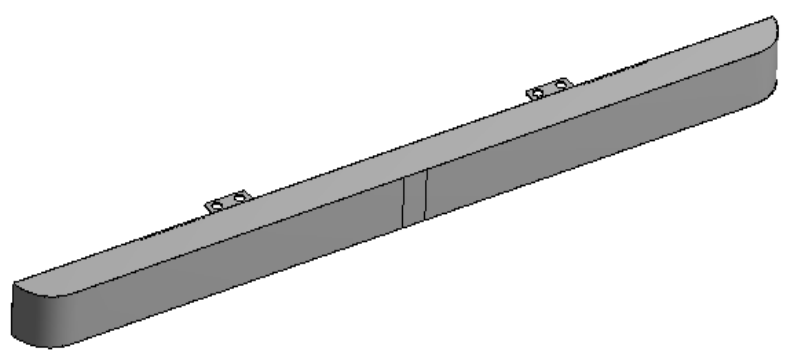

Fig. 1. CATIA model bumper

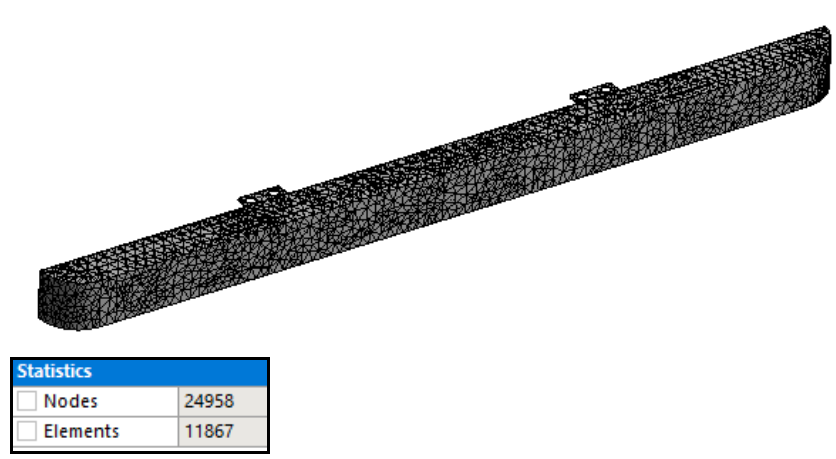

Fig. 2. Meshing of bumper specimen odel bumper

\section{2) Boundary condition}

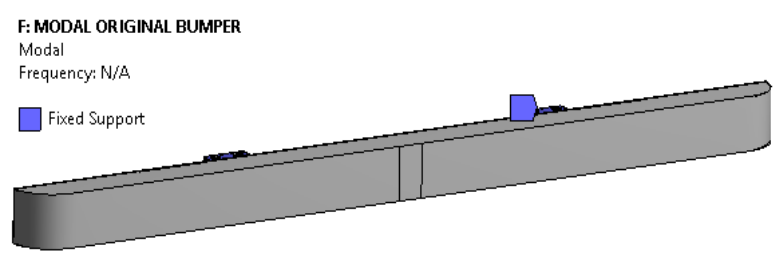

Fig. 3. Boundary condition of bumper specimen

3) Total Deformation

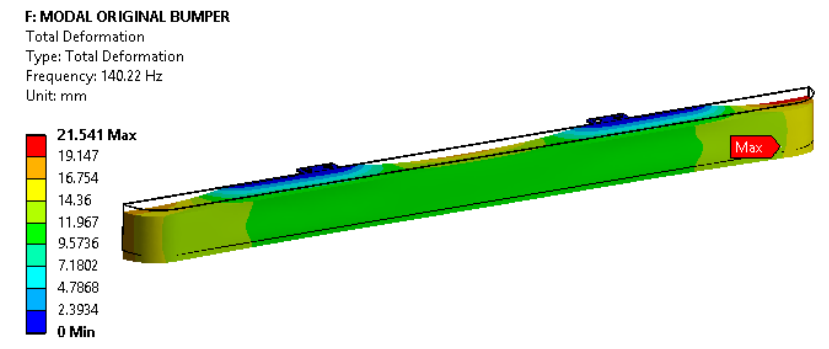

Fig. 4. Total Deformation of bumper mode 1

F: MODAL ORIGINAL BUMPER

Total Deformation 2

Type: Total Deformation Unit: $\mathrm{mm}$

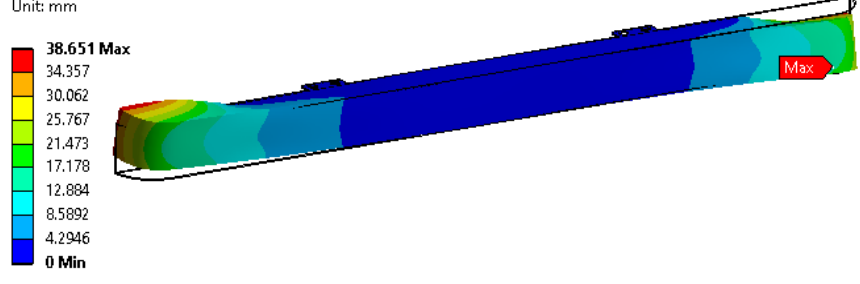

Fig. 5. Total Deformation of bumper mode 2

F: MODAL ORIGINAL BUMPER

Total Deformation 3

Type: Total Deformation

Frequency: $175.25 \mathrm{~Hz}$

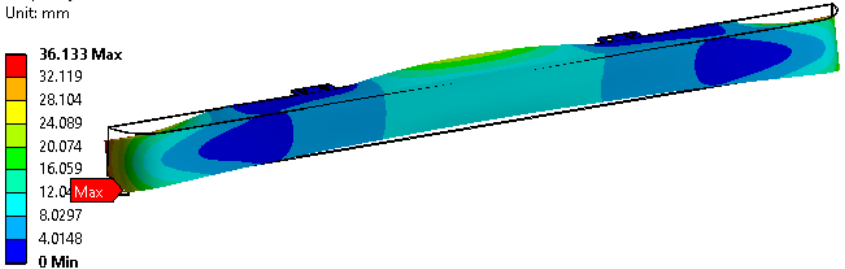

Fig. 6. Total Deformation of bumper mode 3

F: MODAL ORIGINAL BUMPER

Total Deformation 4

Frequency: $180.71 \mathrm{~Hz}$

Unit: $\mathrm{mm}$

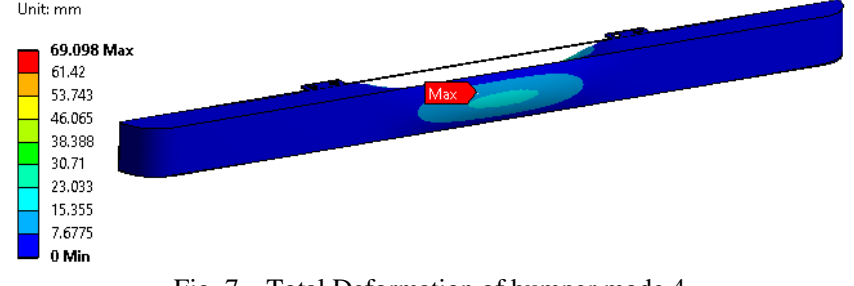

Fig. 7. Total Deformation of bumper mode 4

F: MODAL ORIGINAL BUMPER

Total Deformation 5

Type: Total Deformation

Unit: $\mathrm{mm}$

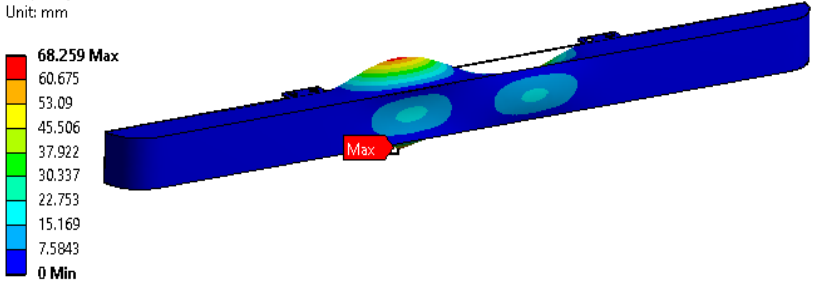

Fig. 8. Total Deformation of bumper mode 5

\section{B. Bumper Geometry with Vertical Stiffeners}

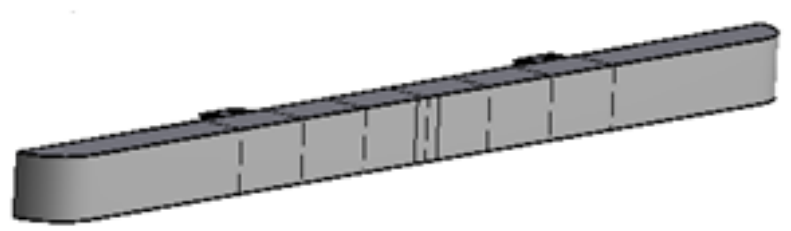




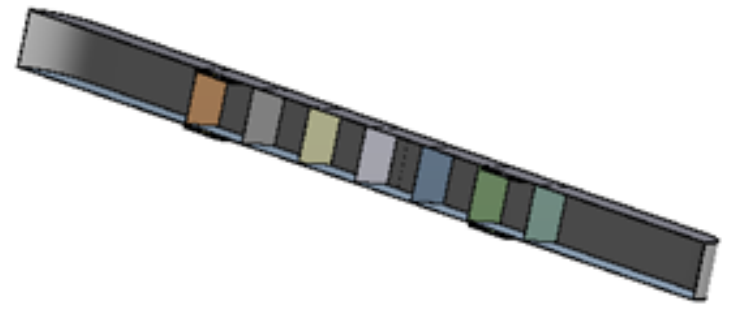

Fig. 9. Bumper with Vertical Stiffeners

\section{1) Total Deformation}

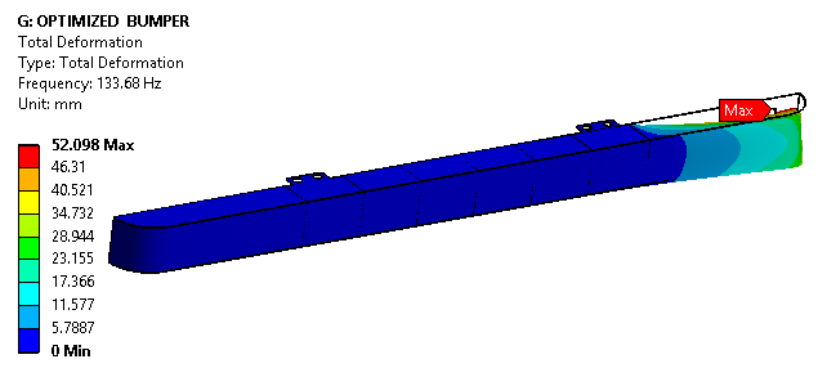

Fig. 10. Total Deformation of Optimized bumper mode 1

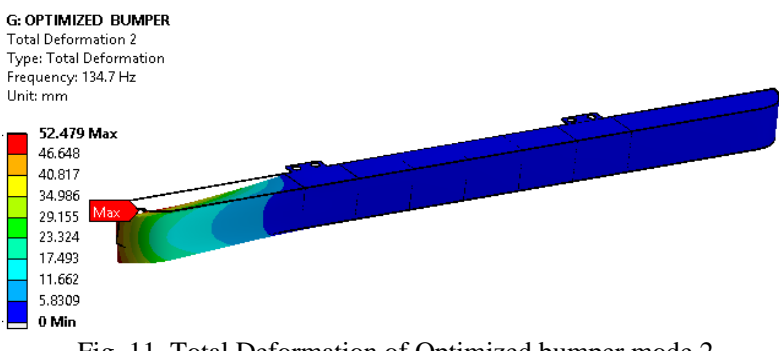

Fig. 11. Total Deformation of Optimized bumper mode 2

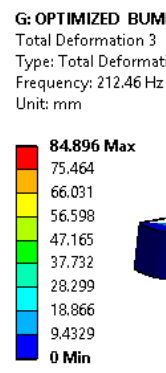

Fig. 12. Total Deformation of Optimized bumper mode 3

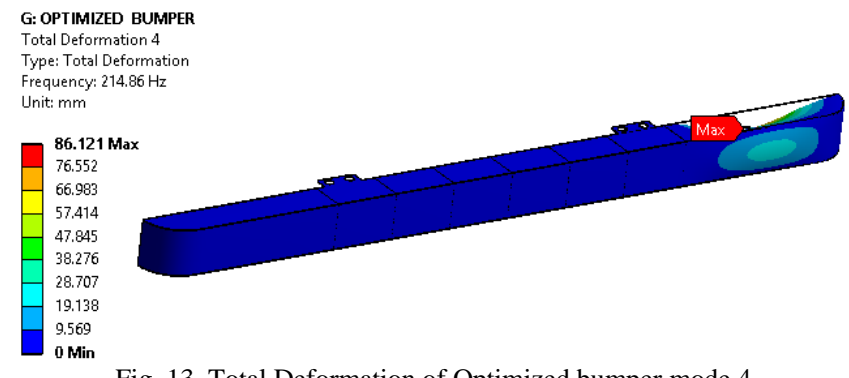

Fig. 13. Total Deformation of Optimized bumper mode 4

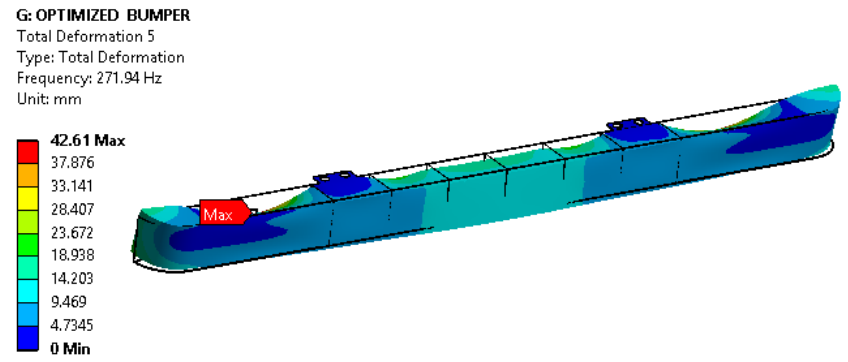

Fig. 14. Total Deformation of Optimized bumper mode 5

\section{EXPERIMENTAL ANALYSIS OF BUMPER}

Experimental analysis is used to find out natural frequency and mode shape of manufactured bumper. This is done by using Fast Fourier Transform (FFT) analyzer.

In this experiment, we used small impact hammer, FFT analyzer, accelerometer, Computer and Dewesoft X software. Bumper was excited by impact hammer, preferably at a point near to the center location of bumper. The input signals captured by a force transducer, which is attached to impact hammer. The resulting vibrations in the bumper are measured by an accelerometer, which is mounted on the bumper preferably in the center area. These signals are subsequently input to the analyzer, which analyzes both input signal from hammer and output signal from accelerometer and then resulting frequency response functions are then transmitted to the computer which is having Dewesoft X software for modal data analysis, which gives natural frequencies and mode shape data.
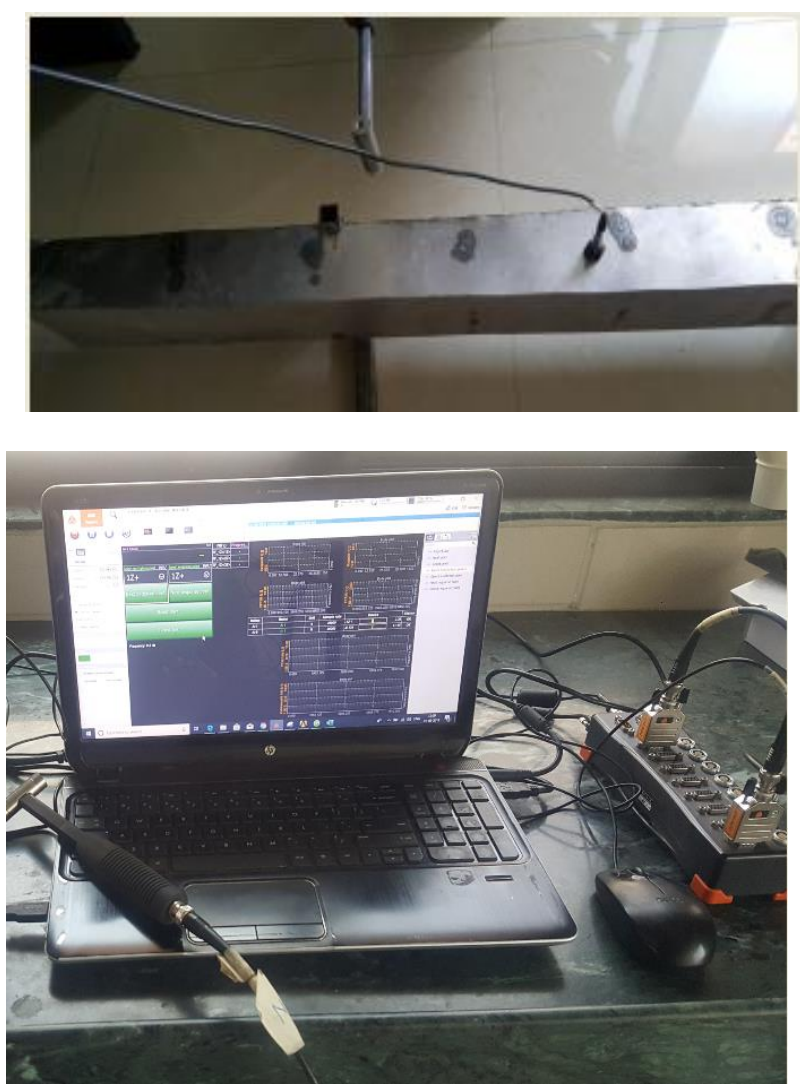


\section{A. Test Frequency Plot}

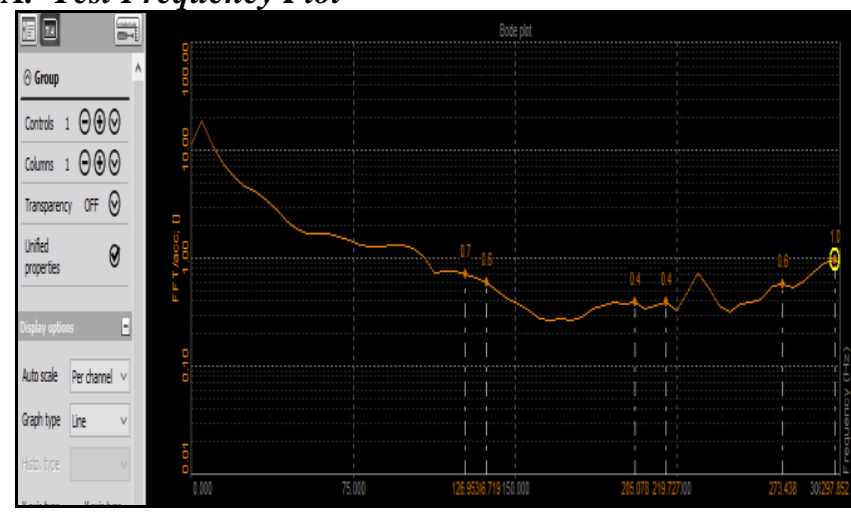

VI. EXPERIMENTAL ANALYSIS RESULTS

A. Comparative Plot of FEA

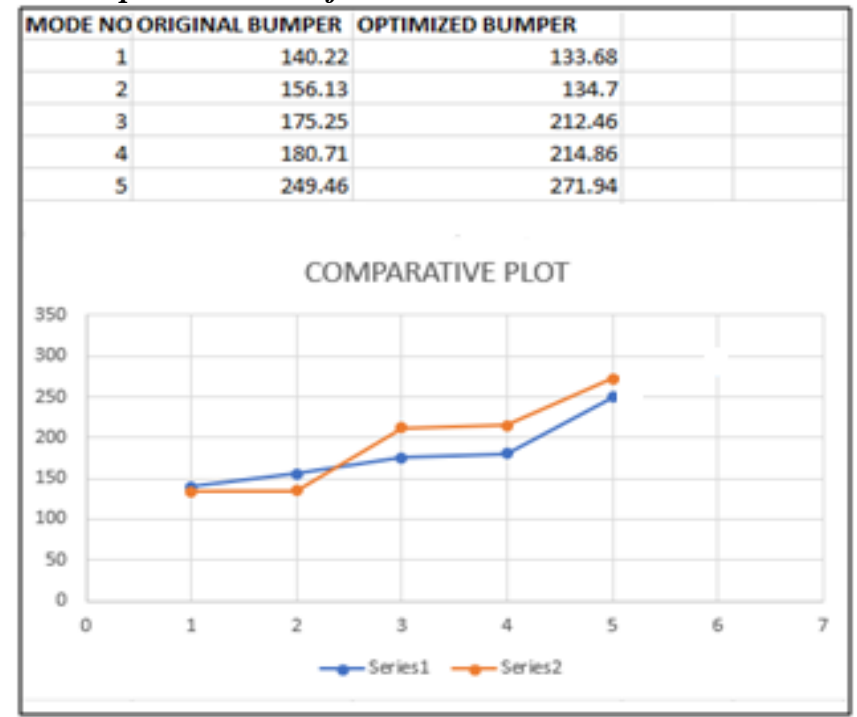

\section{B. Test and FEA Comparison}

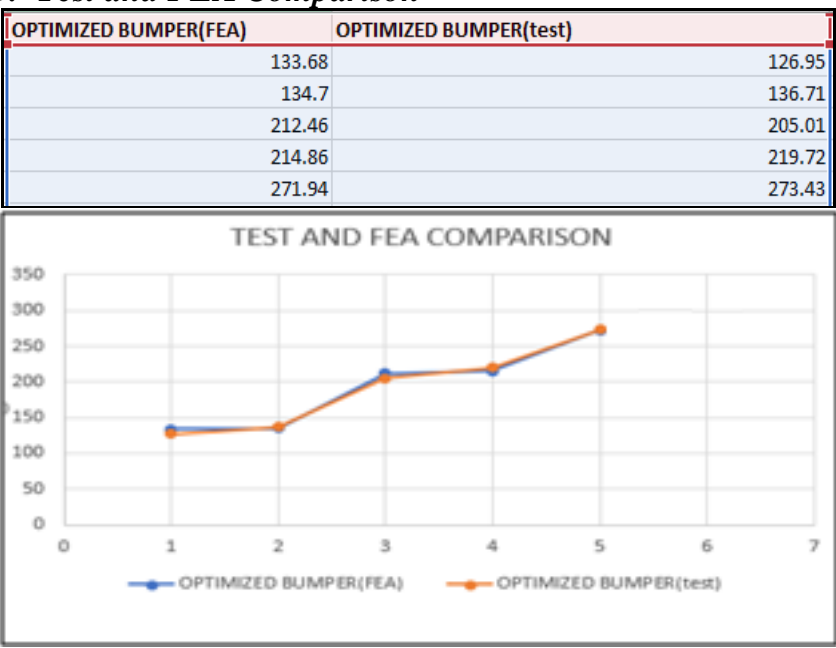

VII. EXPLICIT DYNAMICS ANALYSIS OF BUMPER

A. Velocity of Impact is Considered as $70 \mathrm{Km} / \mathrm{hr}=19.5 \mathrm{~m} / \mathrm{s}$
M: STRUCTURAL STEEL NL ORIGINAL Explicit Dynamic
Time: $1 . e-002$ s

A] Fixed Support

B Velocity

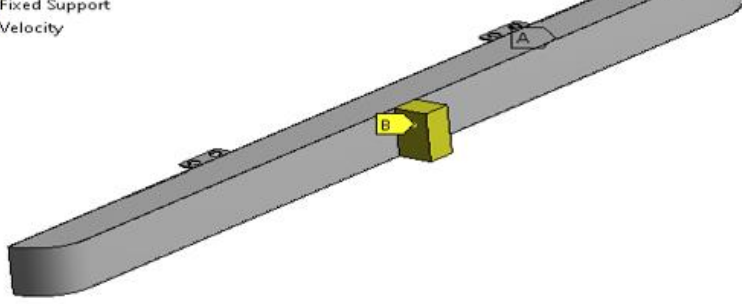

Fig. 15. Boundary Condition of bumper

M: STRUCTURAL STEEL NL ORIGINAL

Velocity

Time: 1.e-002s

Velocity

Components: Free, -19500 , Free $\mathrm{mm} / \mathrm{s}$

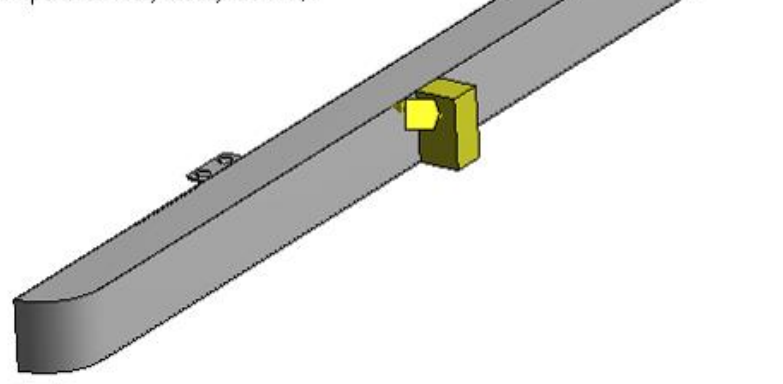

Fig. 16. Velocity Representation for Impact Analysis

\section{B. Average Deformation of $5.42 \mathrm{~mm}$ for bumper without stiffener}

M: STRUCTURAL STEEL NL ORIGINAL

Total Deformation

Type: Total Deformation

Unit: $\mathrm{mm}$

Time: $3.0877 \mathrm{e}-004$

Cycle Number: 10000

Custom

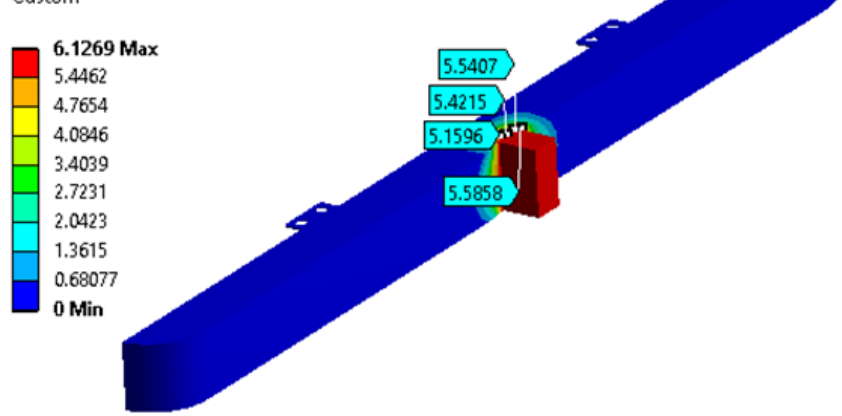

Fig. 17. Deformation of Bumper

M: STRUCTURAL STEEL NL ORIGINAL

Equivalent Stress

Type: Equivalent (von-Mises) Stress

Type: Equiva

Time: $3.0877 \mathrm{e}-004$

Cycle Number: 10000

Custom

Max: 448.33

Max: 4

$\begin{aligned} & 448.33 \\ & 398.52 \\ & 348.7 \\ &-298.89 \\ & 249.07 \\ & 199.26 \\ & 149.44 \\ & 99.63 \\ & 49.815 \\ & 0\end{aligned}$

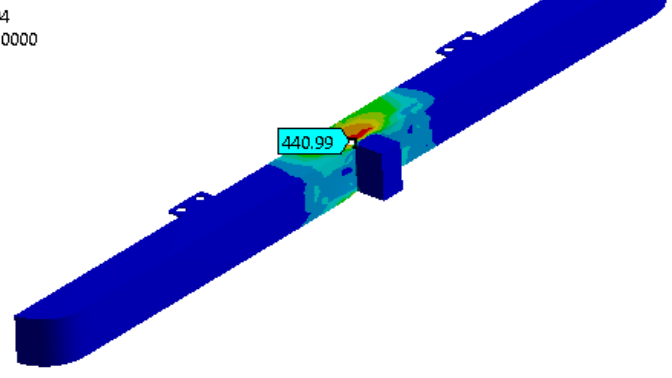

Fig. 18. Stress Analysis of Bumper 


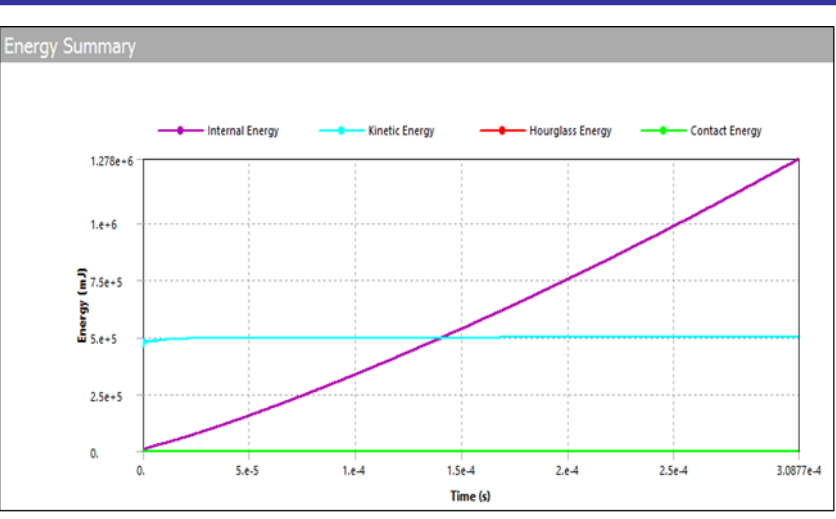

Fig. 19. Energy Summary of Bumper without Stiffener

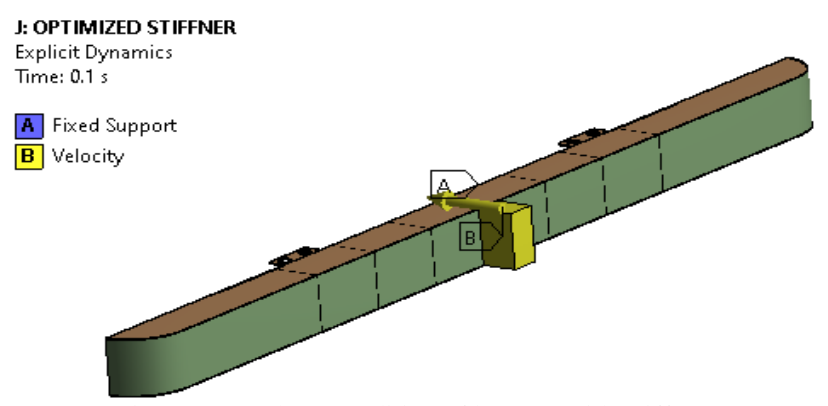

Fig. 20. Boundary Condition of bumper with Stiffener

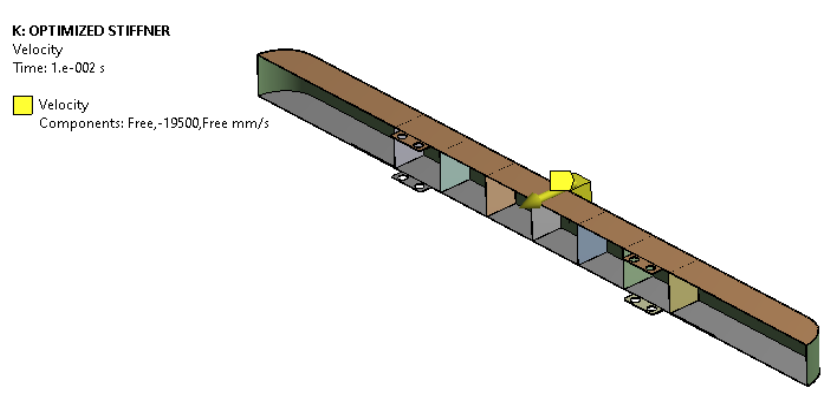

Fig. 21. Velocity Representation for Impact Analysis of bumper with stiffener

\section{Average Deformation of $4.17 \mathrm{~mm}$ for bumper with stiffener}

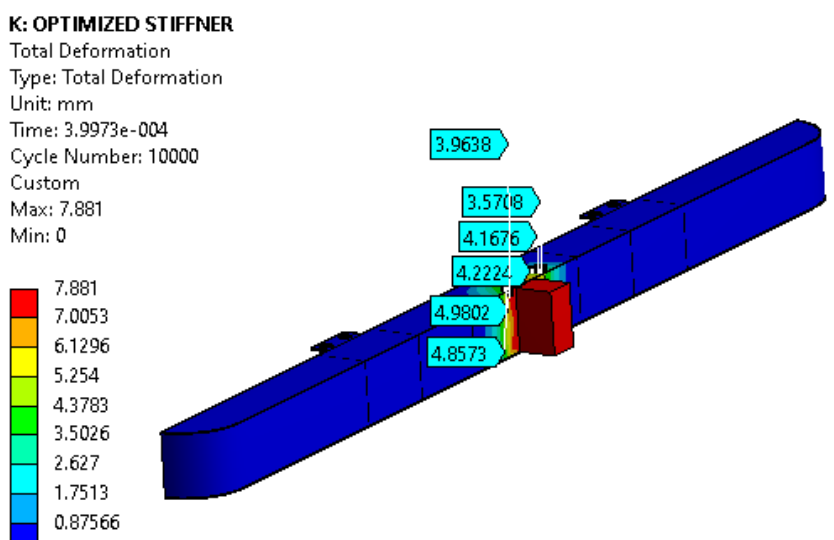

Fig. 22. Deformation of Bumper with Stiffener

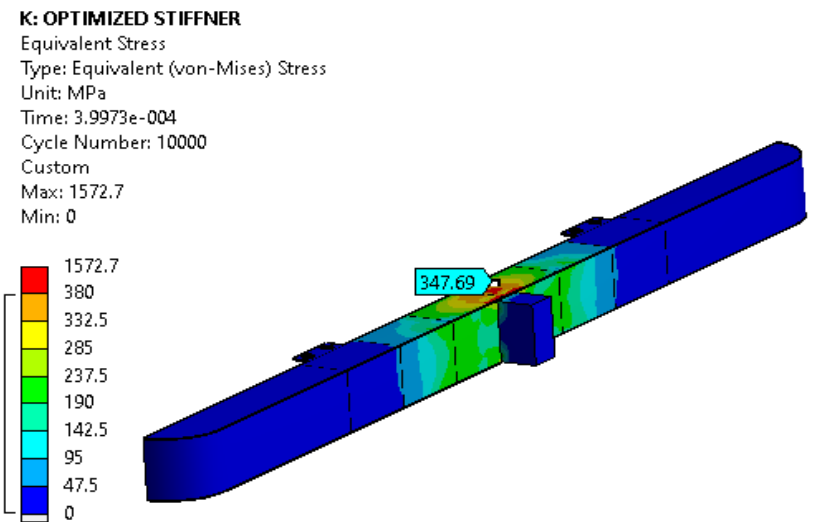

Fig. 23. Stress Analysis of Bumper with Stiffener

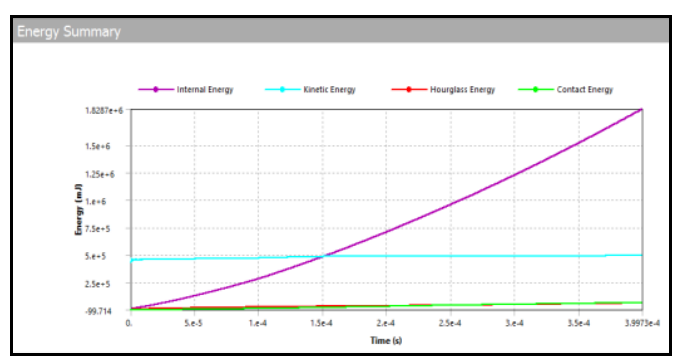

Fig. 24. Energy Summary of Bumper with Stiffener

After comparing Energy Summary graph for Bumper with stiffener and Bumper without stiffener, it is found that Bumper with stiffener have more internal energy absorb capability for respective impact and it is $1.82 \times 10^{\wedge} 6 \mathrm{~mJ}$ compared to $1.27 \times 10^{\wedge} 6 \mathrm{~mJ}$. It is around 25 to $30 \%$ more.

\section{CONCLUSION}

In our research, we build prototype of optimized bumper to study the operation and found easy to manufacture.

In this study found that natural frequencies obtained from our experimental and numerical result are closely matched at most of the modes, addition of stiffener increase the natural frequency because it made the model stiffer and geometry of shape also helps to increase natural frequency by using curve shape and avoiding sharp corner.

From our impact dynamic analysis, we analyzed that the bumper model of optimized shape with stiffener having more energy absorption capacity and proposed to be best from safety point of view.

\section{REFERENCES}

[1] Lu Wei, Eason, B. Noble, and I.N. Sneddon, "On certain integrals of Lipschitz-Hankel "Optimization Design of Inner Structure and Material of Cars Front Bumper Based on Finite Element Method" Jia Yao AU Xiangdong Liu AU - Lei Xing AU - Xingwang Lv AU - Jing Yao PY 2016/11 DA - 2016/11.

[2] Maheshkumar V. Dange, "Design and Analysis of an Automotive Front Bumper Beam for Low-Speed Impact" Dept. of Mechanical Engineering, Sardar Patel COE, Mumbai University, India

[3] Suresh Doddi, "Experimental-Numerical Modal and Impact Analysis of Car Bumper". Mechanical Engineering Dept., EWIT, Bangalore, Karnataka, India

[4] Dr. E.D. Francis, "Design Analysis of Bumper Beam Subjected to Offset Impact Loading for Automotive Applications". Department of Mechanical, Faculty of HITS, Hyderabad India..

[5] Alen John, "Modeling and Analysis of an Automotive Bumper Used for a Low Passenger Vehicle". Department of Mechanical Engineering, 
Mar Baselios College of Engineering \& Technology, Trivandrum, India.

[6] Zhao Liu, Jiahai Lu, Ping Zhu, Lightweight design of automotive composite bumper system using modified particle swarm optimizer, Shanghai Jiao Tong University, Shanghai 200240, PR China.

[7] Javad Marzbanrada, Design and analysis of an automotive bumper beam in low-speed frontal crashes. Masoud Alijanpour a, Mahdi SaeidKiasat, Thin-Walled Structures (2009), 47, 902-911

[8] Emil Evina, Miroslav, Comparison of deformation properties of steel sheets for car body parts, ELSEVIER, Procedia Engineering 48(2012), PP 115-122.
[9] S. Popprath et.al, Experimental modal analysis of a scaled car body for metro vehicle, International congress on sound and vibration,2006.

[10] Di Zhou, Xianhui Wang, Yunbo Zhou, Experimental and numerical investigation on the energy absorption of a bending-straightening structure., 12 Aug 2019.

[11] Chandrakant Rameshchandra Sonawa, Strength enhancement of car front Bumper for slow speed impact by FEA method as per IIHS Regulation. J. Inst. Eng India Ser C (October 2018) 99(5):599-606

[12] Nitesh Joshi, Design and analysis of Front Bumper for Light PassengerVehicles., International Journal for Rapid Research in Engineering Technology \& Applied Science, Vol 2 Issue 4 May2016. 